\title{
ОЦЕНКА ЛЕЧЕНИЯ ПАТОЛОГИИ ВИСОЧНО-НИЖНЕЧЕЛЮСТНОГО СУСТАВА НА ФОНЕ ДИСПЛАЗИИ СОЕДИНИТЕЛЬНОЙ ТКАНИ С ИСПОЛЬЗОВАНИЕМ СИНДРОМА ПСИХОСЕНСОРНО-АНАТОМО-ФУНКЦИОНАЛЬНОЙ ДЕЗАДАПТАЦИИ
}

\author{
(С Иорданишвили А.К., ${ }^{1,2}$, Сериков А.А. ${ }^{2}$, Солдатова Л.Н. ${ }^{2,3}$, Жидких Е.Д. , \\ Овчинников К.А. ${ }^{1}$, Николайчук E.A. ${ }^{2}$
}

\author{
${ }^{1}$ Северо-Западный государственный медицинский университет им. И.И. Мечникова, \\ Санкт-Петербург; ${ }^{2}$ Военно-медицинская академия им. С.М. Кирова, Санкт-Петербург; \\ ${ }^{3}$ Лечебно-диагностический центр «Альфа-Дент», Санкт-Петербург \\ E-mail: masha zu@,mail.ru
}

\begin{abstract}
Изучены особенности личностного реагирования на болезнь в процессе лечения патологии височнонижнечелюстного сустава (ВНЧС) у 52 пациентов (27 мужчин и 25 женщин) в возрасте от 19 до 63 лет, протекающей на фоне дисплазии соединительной ткани. Особенности психологической адаптации пациентов к болезни и при проведении стоматологической реабилитации изучены с учетом тяжести течения патологии височно-нижнечелюстного сустава путем оценки синдрома психосенсорно-анатомо-функциональной дезадаптации (СПСАФД). Установлено, что по мере утяжеления клинической картины патологии ВНЧС у пациентов увеличивалось значение интегрального показателя СПСАФД. Выявлены достоверные различия в личностном реагировании на болезнь при благоприятном исходе лечения патологии ВНЧС. Сделан вывод, что рациональное использование в стоматологической артрологии методики анализа СПСАФД даст возможность его коррекции и явится одним из направлений в повышении удовлетворенности пациентов качеством стоматологической помощи.

Ключевые слова: височно-нижнечелюстной сустав, индексная оценка тяжести патологии, морфометрический индекс височно-нижнечелюстного сустава, обследование стоматологического больного, внутренняя картина болезни, личностное реагирование на болезнь, синдром психосенсорно-анатомо-функциональной дезадаптации.
\end{abstract}

\section{EVALUATION OF MANAGING TEMPOROMANDIBULAR JOINT PATHOLOGY \\ AGAINST THE BACKGROUND OF DYSPLASIA OF CONNECTIVE TISSUE}

WITH THE USE OF PSYCHOSENSORY-ANATOMICAL-FUNCTIONAL-DISADAPTATION SYNDROME Iordanishvili A.K. ${ }^{1,2}$, Serikov A.A. ${ }^{2}$, Soldatova L.N. ${ }^{2,3}$, Zhidkikh E.D. ${ }^{l}$, Ovchinnikov K.A. ${ }^{1}$, Nikolaychuk E.A. ${ }^{2}$

${ }^{1}$ I.I. Mechnikov North-Western Medical State University, St. Petersburg;

${ }^{2}$ S.M. Kirov Military Medical Academy, St. Petersburg; ${ }^{3}$ Medical and diagnostic center "Alfa-Dent", St. Petersburg

The features of personal response to illness in the course of managing temporal and mandibular joint (TMJ) pathology in 52 (27 men and 25 women) aged from 19 up to 63 years, accompanied by dysplasia are studied. The features of patients' psychological adaptation to illness and in carrying out dental rehabilitation are studied taking into account the severity of temporal and mandibular joint pathology by assessing the syndrome of psycho- sensory anatomical-functional disadaptation (SPSAFD). It has been established that with clinical picture of TMJ pathology in patients getting worse the value of SPSAFD integrated indicator has increased. The reliable differences in personal response to illness in favorable outcome of managing TMJ pathology have been revealed. It has been concluded that rational use of the SPSAFD analysis technique in stomatologic arthrology will enable to correct the pathology and will be one of directions in improving patients' satisfaction with the quality ofdental help.

Keywords: a temporal and mandibular joint, index assessment of severity of pathology, a morphometric index of a temporal and mandibular joint, examination of a stomatologic patient, an internal picture of illness, personal response to illness, a syndrome of psycho - sensory anatomical-functional disadaptation.

Заболевания височно-нижнечелюстного сустава (ВНЧС) у пациентов стоматологических лечебно-профилактических учреждений встречаются часто, плохо поддаются лечению и очень мучительны для пациентов, что связано с нарушением функций жевания, откусывания, речи [2, $6,23]$. Одним из важных факторов развития патологии ВНЧС, кроме окклюзионных нарушений [17], являются наследственные дефекты формирования соединительной ткани - дисплазия соединительной ткани (ДСТ) [1, 19]. Доказано, что у лиц, страдающих ДСТ, лечение патологии
ВНЧС с использованием общепринятых методов менее эффективно [7, 12, 15], что связывают со сниженными упругими и прочностными свойствами тканей ВНЧС, приводящими на фоне обычной или повышенной (при нарушении окклюзии) функциональной нагрузки к постоянной микротравматизации суставных элементов, поддерживая хроническое воспаление в ВНЧС $[5,8]$. Именно указанные этиопатогенетические особенности и патоморфологические изменения накладывают отпечаток на клиническую картину заболеваний ВНЧС и характер их течения, что дало 
основание выделить внутренние нарушения ВНЧС, развившиеся у лиц, страдающих ДСТ, в отдельную форму патологии - синдром соединительнотканной дисплазии ВНЧС $[4,19]$. Поэтому вопросы оптимизации диагностики и лечения заболеваний ВНЧС на фоне ДСТ являются актуальными для стоматологической практики.

C прогностической точки зрения врачустоматологу важно знать, какой мотивацией руководствуется пациент, принимая решение начать лечение или отказаться от него при реальных возможностях его осуществления [21, 22]. Поэтому для прогнозирования исхода стоматологической реабилитации лиц, страдающих заболеваниями ВНЧС, в том числе на фоне ДСТ, может играть экспресс-анализ уровня самооценки психологической адаптации пациентов к имеющейся у них патологии ВНЧС, которую дает себе сам больной [14]. Эффективность стоматологической реабилитации при патологии ВНЧС с использованием современных методов лечения, включая фармакотерапию и стоматологическое ортопедическое лечение, существенно возрастает, если врач-стоматолог имеет не только необходимые теоретические знания и мануальные навыки по своей специальности, но и владеет методикой получения от пациента информации о соматических и психических проявлениях заболевания, а также о самооценке пациентом выраженности каждого из этих проявлений [13].

Цель исследования: изучить особенности внутренней картины болезни в ходе стоматологической реабилитации людей, страдающих патологией ВНЧС на фоне ДСТ путем оценки синдрома психосенсорно-анатомо-функциональной дезадаптации.

\section{МАТЕРИАЛЫ И МЕТОДЫ ИССЛЕДОВАНИЯ}

Для изучения особенностей личностного реагирования на болезнь было проведено комплексное обследование и лечение 52 (27 (51,92\%) мужчин и $25(48,08 \%)$ женщин) пациентов в возрасте от 19 до 63 лет, которые обратились на фоне болевой височно-нижнечелюстной дисфункции или артрозо-артрита к врачу-стоматологу и страдали заболеваниями ВНЧС на фоне ДСТ, которая была ранее диагностирована и подтверждена врачамиинтернистами в процессе наблюдения за этими пациентами. Распределение пациентов по полу с учетом возраста представлено в таблице 1 . В ходе исследования, в зависимости от степени тяжести течения патологии ВНЧС, которую определяли согласно имеющимся рекомендациям [11], пациенты были распределены на 3 группы (рис. 1). В 1 группу вошло 13 пациентов, страдающих патологией ВНЧС легкой степени; во 2 группу 28 чел., страдающих патологией ВНЧС средней тяжести; в 3 группу - 11 чел., страдающих тяжелой патологией ВНЧС.

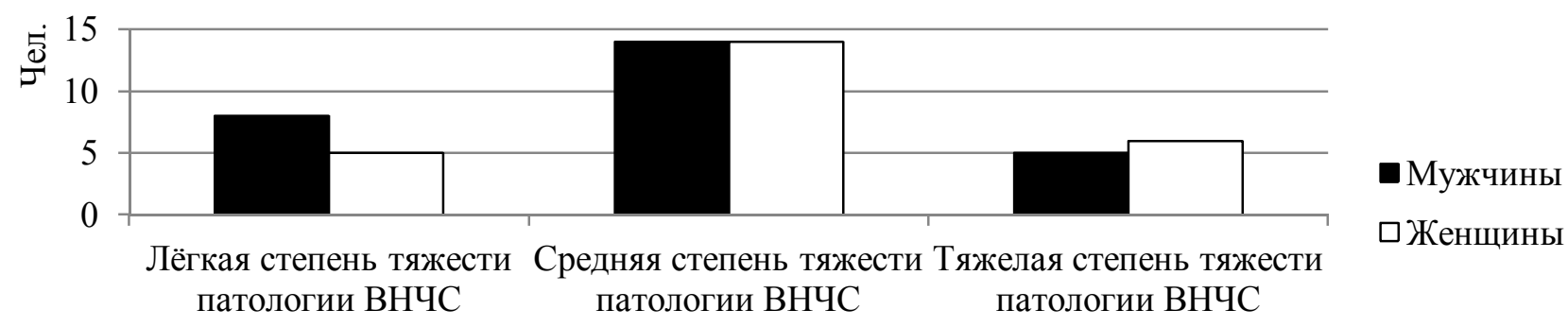

Группа исследования

A.
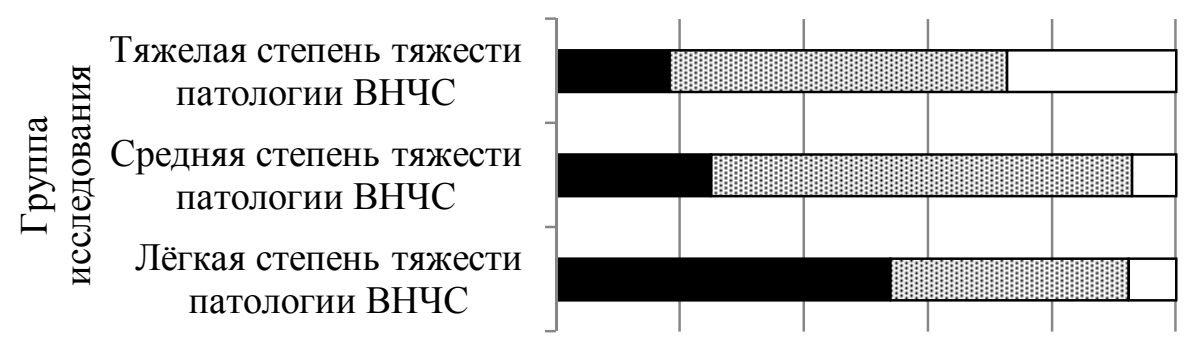

- Молодые

国Лица, среднего возраста

口Пожилые люди

Чел.

Б.

Рис. 1. Распределение пациентов в исследуемых группах с учетом пола (А), а также по возрасту и степени тяжести течения патологии ВНЧС (Б), (чел). 
Количество и возраст людей, подвергнутых стоматологическому обследованию

\begin{tabular}{|c|c|c|c|c|c|c|}
\hline \multicolumn{2}{|c|}{ Молодой возраст (18-39 лет) } & \multicolumn{2}{|c|}{ Средний возраст (40-59 лет) } & \multicolumn{2}{|c|}{ Пожилой возраст (60 лет и старше) } & \multirow{2}{*}{ Всего } \\
\cline { 1 - 5 } мужчины & женщины & мужчины & Женщины & мужчины & женщины & \\
\hline 10 & 6 & 14 & 16 & 3 & 3 & 52 \\
\hline \multicolumn{2}{|c|}{30} & \multicolumn{2}{|c|}{30} & 6 & 52 \\
\hline
\end{tabular}

Выявление, определение интенсивности течения и эффективности лечения патологии ВНЧС осуществляли на основании жалоб, анамнеза, объективных данных, клинического обследования с применением аускультации и клинического индекса дисфункции [11]. Для функциональной оценки органов и тканей жевательного аппарата была использована методика миотонометрии [16]. Лучевое обследование (ортопантомография, КТ, МРТ) проводили для уточнения полученных клинических данных, оценки состояния органов и тканей жевательного аппарата и ВНЧС, а также определения показателей морфометрического индекса ВНЧС [2, 6, 24].

Для оценки личностного реагирования на заболевание при патологии ВНЧС (внутренней картины болезни) была использована сравнительно новая методика анализа структуры и выраженности внутренней картины болезни с использованием «Синдрома психосенсорно-анатомо-функциональной дезадаптации» (СПСАФД) или «Синдрома профессора М.М. Соловьёва старшего» [20]. Согласно этой методике, все проявления внутренней картины заболевания распределяются по 4 кластерам: «П» - психологический (психический), «С»- сенсорный, «А»- анатомический и «Ф»- функциональный. Особенностью СПСАФД является то, что оценку выраженности отдельных симптомов, ощущений, вызывающих дезадаптацию, дают сами пациенты. Для этого используется единая аналогово-балльная шкала самооценки пациентами выраженности отдельных проявлений заболевания (от 1 до 9 баллов: от не беспокоит (1 балл), до слабо (3 балла), умеренно (5 баллов), сильно 97 баллов) и чрезвычайно сильно (9 баллов) беспокоит). Распределение отдельных симптомов, вызывающих у пациентов дезадаптацию, осуществляет врач. Результаты самооценки пациентами выраженности проявления заболевания осуществляли путем учета интегрального показателя выраженности СПСАФД (показатель $\mathrm{S}$, рассчитывался в баллах), а также с учетом структуры интегрального показателя СПСАФД согласно кластерам «П», «С», «А», «Ф» (рассчитывался в баллах). Оценку внутренней картины заболевания у обследуемых осуществляли дважды: до начала стоматологической реабилитации и спустя месяц после завершения курса лечебнопрофилактических мероприятий. Последние включали в себя, с учетом степени тяжести течения патологии ВНЧС, общепринятые функциональные [15], медикаментозные методы [3], в том числе биорегулирующую терапию [10], внутрисуставное введение препарата гиалуроновой кислоты [12], а также ортопедическое стоматологическое лечение (по показаниям) [17, 22, 24].

Полученный в результате исследований цифровой материал обработан на персональной ЭВМ. Использовали специализированный пакет программ для статистического анализа «Statistika for Windows v. 6.0». Оценка значимости различия средних значений и частоты проявления признаков в группах исследования проводилась с помощью параметрических и непараметрических методов оценки гипотез: параметрический критерий $\mathrm{t}$-Стьюдента, непараметрический критерий $\chi^{2}$ Пирсона. Изучение связей между признаками осуществляли с помощью коэффициента корреляции Пирсона.

\section{РЕЗУЛЬТАТЫ ИССЛЕДОВАНИЯ И ИХ ОБСУЖДЕНИЕ}

В ходе исследования как интегральных показателей СПСАФД, так и структуры интегрального показателя, определяющего внутреннюю картину болезни, достоверных половых различий не получено $(\mathrm{p} \geq 0,05)$. Поэтому статистическая обработка цифровых данных в ходе работы выполнена без учета пола. В ходе исследования установлено, что до начала стоматологической реабилитации наименьшие значения интегрального показателя СПСАФД имели пациенты, входившие в 1 группу исследования (рис. 2). Очевидно это было связано с тем, что у них, на фоне легкой формы патологии ВНЧС, имело место слабовыраженная артралгия, а также с ней связанные с ней функциональные нарушения, что не вызывало выраженных расстройств, главным образом, функции жевания. По мере утяжеления клинической картины патологии ВНЧС у пациентов увеличивалось значение интегрального показателя $\mathrm{S}$ СПСАФД $(\mathrm{p} \leq 0,05$; $\mathrm{r}=0,57)$.

Учитывая, что у пациентов всех исследованных групп наличие патологии ВНЧС, которое вызывало не только артралгию, нарушение жевания, но и обусловливало в связи с болезнью некоторые психические переживания, связанные именно с 


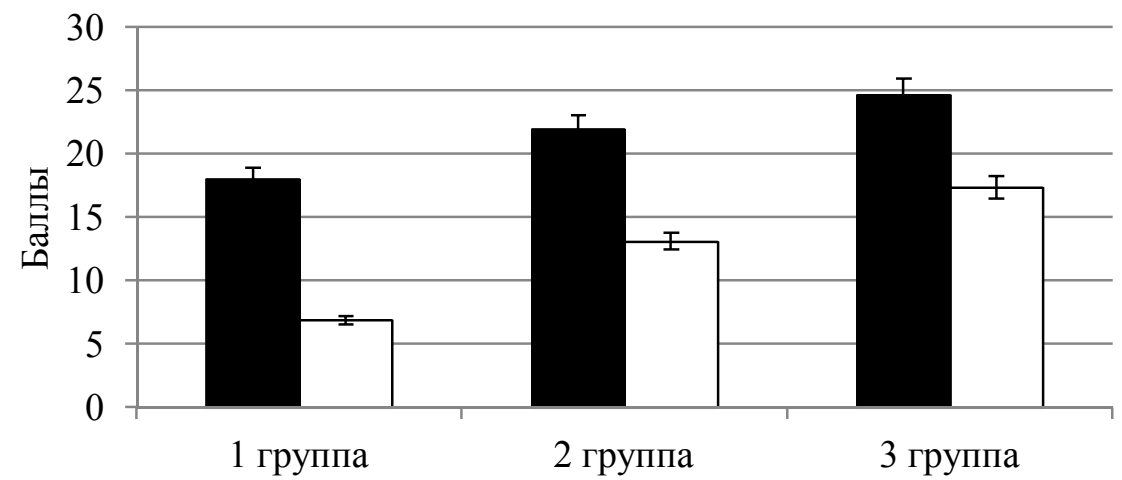

A.
До лечения

口После завершения курса лечебно-профилактических мероприятий

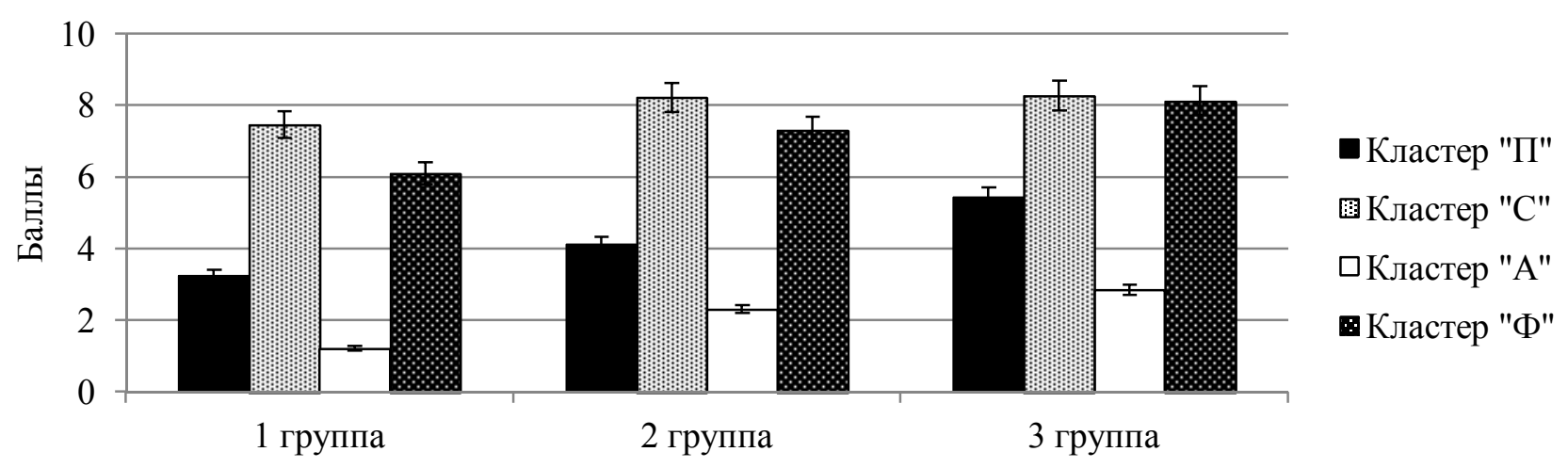

Б.

Рис. 2. Значения интегрального показателя $\mathrm{S}$, определяющего выраженность СПСАФД у пациентов исследованных групп до и после лечения (А) (баллы), и структура интегрального показателя S, определяющего выраженность симптомов заболевания в отдельных кластерах при исследовании СПСАФД у обследованных пациентов до лечения (Б) (баллы).

наличием болевого синдрома, звуковыми феноменами (хруст, щелканье) со стороны ВНЧС, а также нарушением жевательной функции, отмечены наибольшие значения выраженности заболевания в кластерах «С» и «Ф», в меньшей степени «П» (рис. 2), по самооценке выраженности отдельных симптомов, ощущений, вызывающих у пациентов дезадаптационные нарушения. Наименьшие изменения в указанных кластерах отмечены у лиц 1 группы исследования, наибольшие - у лиц, страдающих тяжелыми формами патологии ВНЧС, то есть у лиц 3 группы исследования ( $\mathrm{p} \leq 0,05 ; \mathrm{r}=0,49)$. По данным интегрального показателя СПСАФД можно констатировать, что при средней и тяжелой степени течения патологии ВНЧС у пациентов, независимо от их возраста ( $\mathrm{p} \geq 0,05)$, отмечается нарушение приспособляемости к условиям существования, то есть состояние дезадаптации. Это, безусловно, неблагоприятно влияет на результат проводимого лечения. На основании этого специалисты рекомендуют в таких ситуациях привлекать к лечению пациентов, страдающих патологией ВНЧС, психолога, психотерапевта или клинического фармаколога $[4,17]$.

На рисунке 3 представлены сведения о кли- нической эффективности лечения патологии ВНЧС у обследованных пациентов трех групп. Проведенные лечебно-профилактические мероприятия, независимо от возраста пациентов $(\mathrm{p} \geq 0,05)$, были наиболее эффективны у лиц, страдавших легкой степенью тяжести патологии ВНЧС (рис. 4). Это связано с тем, что у них, по данным морфометрического индекса ВНЧС, отмечено наиболее благоприятное анатомическое строение ВНЧС.

Лица 2 группы, спустя месяц после лечения, практически не имели сенсорных и функциональных нарушений, за исключением наличия звуковых феноменов (хруст, щелканье) со стороны ВНЧС, а также некоторого затруднения при пережевывании пищи, так как известно, что ВНЧС, несомненно, претерпевает с возрастом определенные морфологические изменения (рис. 4), особенно при патологии окклюзии [9, 17]. Анализ значений СПСАФД у пациентов 2 группы, при благоприятном течения патологии ВНЧС в результате проведенного лечения, позволил отметить, что, несмотря на снижение интегрального показателя S СПСАФД (рис. 3), выявлены повышенные значения выраженности некоторых 


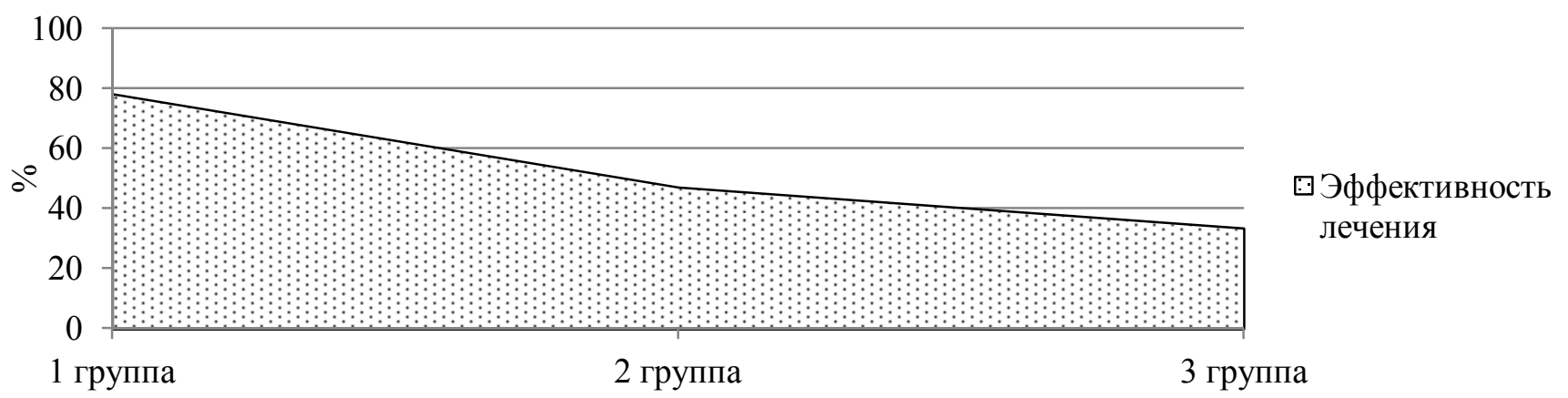

Группы исследования

A.

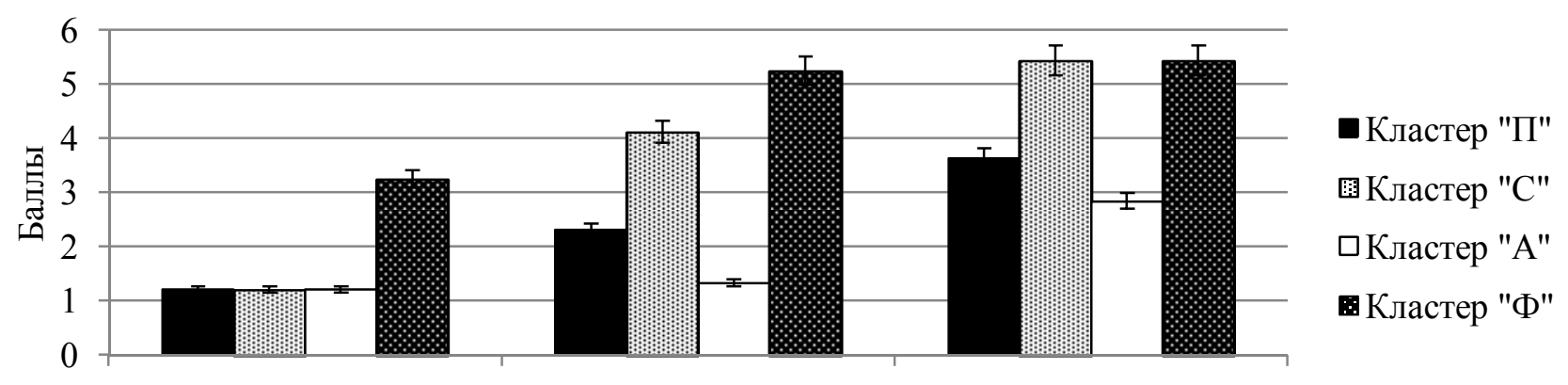

1 группа

2 группа

3 группа

Б.

Рис. 3. Показатели эффективности лечения патологии ВНЧС на фоне ДСТ (\%) у пациентов исследованных групп (А) и структура интегрального показателя $\mathrm{S}$, определяющего выраженность симптомов заболевания в отдельных кластерах при исследовании СПСАФД у обследованных пациентов спустя месяц после завершения лечебно-профилактических мероприятий (Б) (баллы).

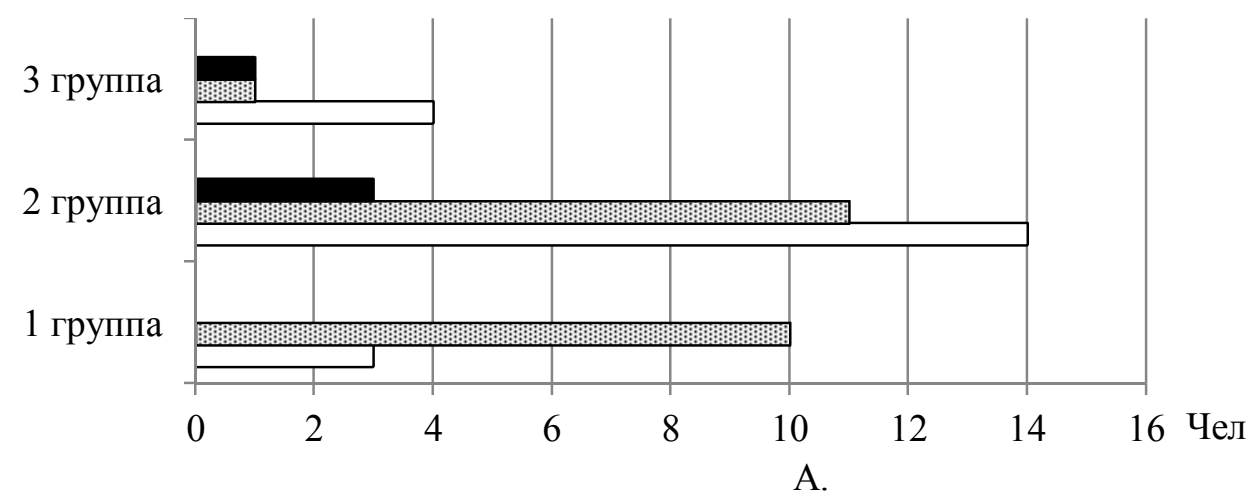

Значения морфометрического индекса

0,81-0,88 усл. ед. 图 0,7-0,8 усл. ед. $\square 0,49-0,69$ усл. ед.

A.

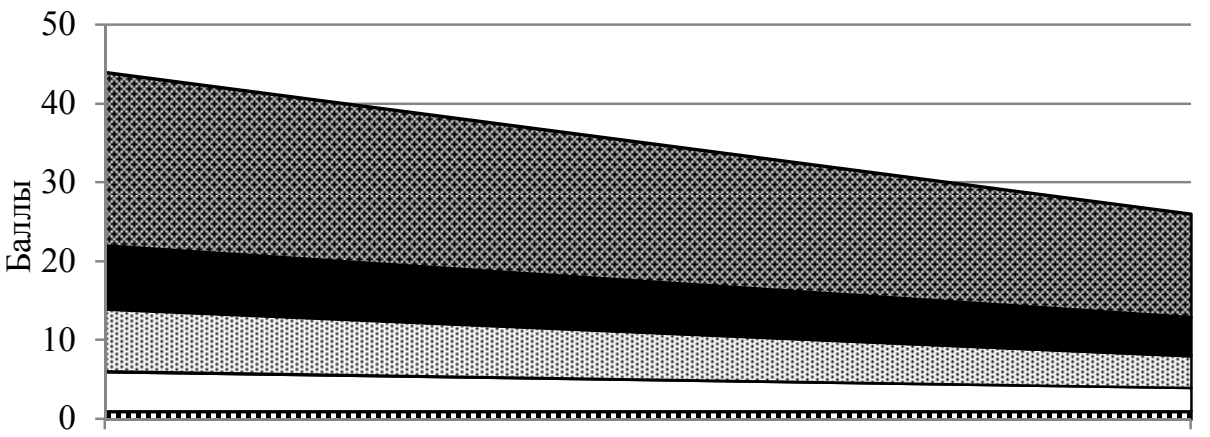

囚нтегральный показатель S

- Кластер "Ф"

图Кластер "C"

口Кластер "П"

шКластер "А"

1 сутки

7 сутки

Б.

Рис. 4. Распределение пациентов в исследованных группах в зависимости от показателя значений морфометрического индекса ВНЧС (a), (чел.) и динамика интегрального показателя $\mathrm{S}$ и выраженность симптомов патологии ВНЧС в процессе лечения в отдельных кластерах при исследовании СПСАФД у пациента Ш., 63 лет, из 3-й группы исследования (б), (баллы). 
симптомов патологии ВНЧС в кластерах «Ф» и «С» (рис. 5). Это свидетельствовало о нарушении жевания, а также болевых ощущениях со стороны ВНЧС, очевидно, вследствие анатомических изменений в ВНЧС (рис. 4).

У пациентов 3 группы, несмотря на высокие значения интегрального показателя СПСАФД после лечения (рис. 2), отмечено достоверное снижение его значения ( $\mathrm{p} \leq 0,01)$, что свидетельствовало о положительной динамике клинической картины патологии ВНЧС по самооценке состояния своего здоровья пациентами. Очевидно, имеющиеся у них анатомические изменения ВНЧС (рис. 4) не позволяли в полной степени купировать имеющиеся симптомы со стороны ВНЧС. Отмечено, что у лиц 3 группы, кроме выявляемых повышенных значений выраженности симптомов патологии ВНЧС в кластерах «Ф» и «С», coхранялись повышенные значения симптоматики, входящей в кластер «П», связанные с длительностью течения патологии ВНЧС и меньшей эффективностью ее лечения, что обусловливало у них наличие тревоги за результат лечения (рис. 3). Этим объясняются стабильно высокие интегральным показатели СПСАФС, а также повышенные показатели СПСАФД в кластере «П» на всем протяжении наблюдения за пациентами 3 группы исследования (рис. 4).

Таким образом, в ходе проведенного клинического исследования установлена корреляция между показателями СПСАФД, степенью тяжести течения патологии ВНЧС на фоне ДСТ $(\mathrm{r}=0,52 ; \mathrm{p} \leq 0,05)$, а также эффективностью лечения рассматриваемой патологии $(\mathrm{r}=0,36 ; \mathrm{p} \leq 0,05)$, что свидетельствует о важности показателей личностного реагирования на болезнь в оценке проявлений заболеваний ВНЧС и эффективности их лечения.

Таким образом, использование СПСАФД при заболеваниях ВНЧС, в том числе протекающих на фоне ДСТ, позволило выявить особенности психологической адаптации пациентов к рассматриваемой патологии, а также оценить личностное реагирование на заболевание. Получены достоверные различия в личностном реагировании на болезнь патологии ВНЧС в зависимости от степени тяжести ее течения и эффективности лечения, а также анатомических изменениях в ВНЧС, обусловленных возрастом пациента, патологией ВНЧС и окклюзии. Обычно при эффективном лечении патологии ВНЧС легкой степени тяжести на фоне ДСТ не создает пациентам каких либо проблем и не вызывает психологических изменений. В основном во время острого периода их беспокоит только болевой синдром и обусловленные им функциональные нарушения, после купирования которого показатели СПСАФД нор- мализуются. Значение интегрального показателя $\mathrm{S}$, определяющего выраженность СПСАФД во всех его кластерах, при патологии ВНЧС легкой степени обычно не превышает 17-19 баллов, а после лечения 5-7 баллов. У лиц, страдающих патологией ВНЧС средней тяжести на фоне ДСТ, значение интегрального показателя $\mathrm{S}$ составляло на момент обращения пациента к врачу в среднем 21-22 балла, особенно за счет кластеров «С» и «Ф», что свидетельствует о затруднениях, которые, согласно самооценке, обусловлены нарушением функции жевания и болевым синдромом. При эффективном лечении патологии ВНЧС, несмотря на снижение интегрального показателя СПСАФД в этой группе пациентов, сохранялись повышенные значения показателей в кластерах «Ф» и «С», что свидетельствует о проблемах с жеванием и болевых ощущениях со стороны ВНЧС, которые могут быть обусловлены анатомическими изменениями ВНЧС. Анализ внутренней картины болезни при патологии ВНЧС тяжелой степени на фоне ДСТ показал, что у таких людей имеется состояние дезадаптации (интегральный показатель $\mathrm{S}=24-25$ баллам) не только при их первичном обращении к врачу (наличие болевого синдрома, затруднения жевания), но и после успешной стоматологической реабилитации. Это обусловлено сохраняющимися дисфункциональными изменениями со стороны ВНЧС (повышенные значения в кластерах «Ф» и «С»). Кроме того, у таких пациентов диагностируются повышенные значения в кластере «П», которые обусловливаются психологическими переживаниями, связанными с длительностью течения патологии ВНЧС, незначительной эффективностью ее лечения, что и определяет у них наличие тревоги за результат лечения. У таких лиц значение интегрального показателя $\mathrm{S}$, определяющего выраженность СПСАФД, независимо от возраста, даже при благоприятном лечении обычно превышает 16-17 баллов, что определяет целесообразность привлечения к их лечению психолога, психотерапевта или клинического фармаколога. Таким образом, представляется, что рациональное использование в клинической стоматологии методики анализа СПСАФД дает возможность его коррекции и является одним из важных направлений в повышении удовлетворенности пациентов качеством стоматологической помощи.

\section{ЛИТЕРАТУРА / REFERENCES}

1. Бабич В.В., Иорданишвили А.К., Рыжак Г.А. Реабилитационный потенциал организма у больных пожилого и старческого возраста с проявлениями болевой дисфункции височно-нижнечелюстного сустава // Клиническая геронтология. - 2014. T. 20, № 7-8. - C. 35-37. [Babich V.V., Jor- 
danshvili A.K., Ryzhak G.A. Rehabilitation potential of the organism in elderly and senile manifestations pain dysfunction of the temporomandibular joint. Klinicheskaya gerontologiya. 2014; 20(7-8): 35-37 (in Russ.)].

2. Гайворонский И.В., Сериков А.А., Иорданишвили А.К., Гайворонская М.Г., Солдатова Л.Н. Височно-нижнечелюстной сустав: морфология и клиника дисфункции. - СПб. : Изд-во «Элмор», 2013. - 135 c. [Gayvoronskiy I.V., Serikov A.A., Iordanishvili A.K., Gayvoronskaya M.G., Soldatova L.N. Temporomandibular joint: morphology and dysfunction clinic. SPb. : Izd-vo «Elmor»; 2013: 135 (in Russ.)].

3. Дмитриева-Носова В.Ф. Рациональное использование препаратов системного действия в комплексной терапии стоматологических заболеваний // Основы клинической стоматологии / Под ред. проф. А.К. Иорданишвили. - М. : Медицинская книга, 2010. - С. 419-433. [DmitriyevaNosova V.F. Rational use of drugs of systemic action in the complex therapy of dental diseases. in Basics of clinical dentistry. A.K. Iordanishvili, editor. - M. : Meditsinskaya kniga; 2010: 419-433 (in Russ.)].

4. Иванов А.С., Богдашева Н.И., Самсонов В.В., Иорданишвили А.К. Медико-социальный и психосоматический статус геронтостоматологических больных // Успехи геронтологии. - 2013. - Т. 26, № 4. C. 714-716. [Ivanov A.S., Bogdasheva N.I., Samsonov V.V., Iordanishvili A.K. Medico-social and psychosomatic status of gerontostomatologic patients. Uspekhi gerontologii. 2013; 26(4): 714-716 (in Russ.)].

5. Иорданишвили А.К., Удальиова Н.А., Самсонов B.В., Сериков А.А., Рыжак Г.А. Диагностика и лечение заболеваний височно-нижнечелюстного сустава в амбулаторно-поликлинических учреждениях. - СПб. : Нордмедиздат, 2012. - 132 с. [Iordanishvili A.K., Udal'tsova N.A., Samsonov V.V., Serikov A.A., Ryzhak G.A. Diagnosis and treatment of diseases of the temporomandibular joint in outpatient clinics. SPb. : Nordmedizdat; 2012: 132 (in Russ.)].

6. Иорданишвили А.К., Солдатова Л.Н., Рыжак Г.А. Диагностика и лечение заболеваний височнонижнечелюстного сустава и жевательных мышц у людей пожилого и старческого возраста. - СПб. : МАНЭБ - Нордмедиздат, 2011. - 134 c. [Iordanishvili A.K., Soldatova L.N., Ryzhak G.A. Diagnosis and treatment of diseases of the temporomandibular joint and masticatory muscles in elderly and senile people. $\mathrm{SPb}$. : MANEB - Nordmedizdat; 2011: 134 (in Russ.)].

7. Иорданишвили А.К. Основы стоматологической артрологии: учебное пособие. - СПб. : Изд-во «Человек», 2018. - 176 c. [Iordanishvili A.K. Basics of dental arthrology: a tutorial. SPb. : Izd-vo «CHelovek»; 2018: 176 (in Russ.)].

8. Иорданишвили А.К. Клиническая ортопедическая стоматология. - М. : МЕДпресс-информ, 2007. 248 c. [Iordanishvili A.K. Clinical orthopedic dentistry. M. : MEDpress-inform; 2007: 248 (in Russ.)].

9. Иорданишвили А.К., Самсонов В.В. Характеристика утраты зубов у людей различных возрастных групп // Экология и развитие общества. - 2012. № 3 (5). - C. 73-74. [Iordanishvili A.K., Samsonov V.V. Characteristics of tooth loss in people of different age groups. Ekologiya i razvitiye obshchestva. 2012; (3(5)): 73-74 (in Russ.)].

10. Иорданишвили А.К., Слугина А.Г., Сериков А.А., Самсонов В.В., Рыжак Г.А. Пептидная биорегуляция репаративного остеогенеза и остеоинтеграции: миф, реальность или перспективное будущее // Российский вестник дентальной имплантологии. 2015. - № 1 (31). - C. 25-30. [Iordanishvili A.K., Slugina A.G., Serikov A.A., Samsonov V.V., Ryzhak G.A. Peptide bio reparative osteogenesis and osseointegration: myth, reality or a promising future. Rossiyskiy vestnik dental'noy implantologii. 2015; (1(31)): 25-30 (in Russ.)].

11. Иорданишвили А.К., Овчинников К.А., Солдатова Л.Н., Сериков А.А., Самсонов В.В. Оптимизация диагностики и оценки эффективности лечения заболеваний височно-нижнечелюстного сустава и жевательных мышц в стоматологической практике // Вестник Северо-Западного государственного медицинского университета. - 2015. - Т. 7, № 4. C. 31-37. [Iordanishvili A.K., Ovchinnikov K.A., Soldatova L.N., Serikov A.A., Samsonov V.V. Optimization of diagnosis and assessment of effective treatmentof diseases of the temporomandibular joint and masticatory musclesin dental practice. Vestnik Severo-Zapadnogo gosudarstvennogo meditsinskogo universiteta. 2015; 7(4): 31-37 (in Russ.)].

12. Иорданишвили А.К., Сериков А.А., Овчинников К.А. Оценка эффективности внутрисуставного введения препарата гиалуроновой кислоты при заболеваниях височно-нижнечелюстного сустава и дисплазии соединительной ткани // Институт стоматологии. - 2016. - Т. 71, № 2. - С. 57-59. [Iordanishvili A.K., Serikov A.A., Ovchinnikov K.A. Evaluation intraarticular injection of hyaluronic acid at diseases temporomandibular joint and connective tissue dysplasia. Institut stomatologii. 2016; 71(2): 57-59 (in Russ.)].

13. Иорданишвили А.К., Сериков А.А. Стоматологическая артрология как междисциплинарная проблема: методологические аспекты диагностики заболеваний // Пародонтология. - 2017. - Т. 22, № 1 (82). - C. 20-26. [Iordanishvili A.K., Serikov A.A. Dental arthrology as interdisciplinary problem: methodological aspects of a disease diagnosing. Parodontologiya. 2017; 22(1(82)): 20-26 (in Russ.)].

14. Иорданишвили А.К., Толмачев И.А., Альшевский В.В., Поленс А.А., Сериков А.А. Клиникоэкспертные аспекты лечения заболеваний височнонижнечелюстного сустава в амбулаторных медицинских организациях // Медицинская экспертиза и право. - 2012. - № 6. - С. 34-39. [Iordanishvili A.K., Tolmachev I.A., Al'shevskiy V.V., Polens A.A., Serikov A.A. Clinical and expert aspects of the treatment of diseases of the temporomandibular joint in outpatient medical organizations. Meditsinskaya ekspertiza i pravo. 2012; (6): 34-39 (in Russ.)].

15. Иорданишвили А.К., Рыжак Г.А., Самсонов В.В., Солдатова Л.Н. Лечение заболеваний височно- 
нижнечелюстного сустава у людей пожилого и старческого возраста: методич. рекомендации. СПб. : Нордмедиздат, 2012. - 10 c. [Iordanishvili A.K., Ryzhak G.A., Samsonov V.V., Soldatova L.N. Treatment of diseases of the temporomandibular joint in the elderly and senile age: method. recommendations. SPb. : Nordmedizdat; 2012: 10 (in Russ.)].

16. Костур Б.К. Возрастные показания к выбору комплекса методов исследования функции жевательного аппарата: метод. рекомендации. - Л. : Медицина, 1978. - 32 с. [Kostur B.K. Age indications for the choice of a set of methods for the study of the function of the chewing apparatus: method. recommendations.. L. : Meditsina; 1978: 32 (in Russ.)].

17. Приказ Министерства здравоохранения и социального развития Российской Федерации от 20 июля 2007 г. № 488 «Об утверждении Административного регламента Федеральной Службы по надзору в сфере здравоохранения и социального развития по выдаче разрешений на применение новых медицинских технологий». [Order of the Ministry of Health and Social Development of the Russian Federation dated July 20, 2007 No. 488 "On approval of the Administrative Regulations of the Federal Service for Supervision in the Sphere of Health and Social Development for issuing permits for the use of new medical technologies" (in Russ.)].

18. Рубинов И.С. Физиологические основы стоматологии. - Л. : Медицина, 1970. - 333 с. [Rubinov I.S. Physiological basis of dentistry. L. : Meditsina; 1970: 333 (in Russ.)].

19. Савченко Р.К., Ивасенко П.И. Синдром соединительнотканной дисплазии височнонижнечелюстного сустава // Заболевания, повреждения и опухоли челюстно-лицевой области: рук-во для врачей / под ред. проф. А.К. Иорданишвили. - СПб. : СпецЛит, 2007. - С. 268-272. [Savchenko R.K., Ivasenko P.I. The syndrome of connective tissue dysplasia of the temporomandibular joint. in Diseases, injuries and tumors of the maxillofacial area: a guide for doctors. A.K. Iordanishvili, editor. SPb. : SpetsLit; 2007: 268-272 (in Russ.)].

20. Соловьёв М.М., Ярёменко А.И., Исаева Е.Р., Малкова Е.Е., Орехова Л.Ю., Фадеев Р.А., Ткаченко Т.Б., Накатис Я.А., Трофимов В.И., Седов В.М., Трезубов В.Н., Антонова И.Н., Потапчук А.А., Соловьева А.М., Васильев С.В., Соловьев М.Мих., Карпищенко С.А., Хаџкевич Г.А., Калакуцчкий Н.В.,
Горбачева И.А., Шапорова Н.Л., Алехова Т.М., Ванчакова Н.П. Использование «Синдрома психосенсорно-анатомо-функциональной дезадаптации» в лечебно-диагностическом, учебно-образовательном и воспитательном процессах: пособие для преподавателей и врачей / Под ред. С.Ф. Багиенко, А.И. Ярёменко, А.А.Скоромца. - СПб. : Изд-во СПб ГМУ им. акад. И.П. Павлова, 2015. - 36 с. [Solov'yëv M.M., Yaryomenko A.I., Isayeva E.R., Malkova E.E., Orekhova L.Yu., Fadeyev R.A., Tkachenko T.B., Nakatis YA.A., Trofimov V.I., Sedov V.M., Trezubov V.N., Antonova I.N., PotapchukA.A., Solov'yeva A.M., Vasil'yev S.V., Solov'yev M.Mikh., Karpishchenko S.A., Khatskevich G.A., Kalakutskiy N.V., Gorbacheva I.A., Shaporova N.L., Alekhova T.M., Vanchakova N.P. The use of "Psychosensory-anatomical-functional-disadaptation syndrome " in the medical-diagnostic, educational, educational process: a manual for teachers and doctors. S.F. Bagiyenko, A.I. Yaryomenko, A.A. Skoromets, editors. SPb. : Izd-vo SPb GMU im. akad. I.P. Pavlova; 2015: 36 (in Russ.)].

21. Соловьёв М.М., Орехова Л.Ю. Симпозиум «Первые итоги апробации использования синдрома психосенсорно-функциональной дезадаптации в стоматологии и смежных дисциплинах // Пародонтология. - 2014. - Т. 19, № 2 (71). - С. 40. [Solov'yov M.M., Orekhova L.Yu. Symposium "first results of testing the use of psychosensory-functionaldisadaptation syndrome in dentistry and related disciplines. Parodontologiya. 2014; 19(2(71)): 40 (in Russ.)].

22. Цимбалистов А.В., Жданюк И.В., Иорданишвили A.K. Стоматологическая реабилитация: ошибки и осложнения. - СПб. : Нордмедиздат, 2011. 144 c. [Tsimbalistov A.V., Zhdanyuk I.V., Iordanishvili A.K. Dental rehabilitation: errors and complications. SPb. : Nordmedizdat; 2011: 144 (in Russ.)].

23. Ahn S.J., Lee S.J., Kim T.W. Orthodontic effects on dentofacial morphology in women with bilateral TMJ disk displacement // Angle Orthod. - 2007. - Vol. 77, $\mathrm{N} 2$ 2 - P. 288-295. - DOI: 10.2319/00033219(2007)077[0288:OEODMI]2.0.CO;2.

24. Farman A.G., Scarfe W.C. The basics of maxillofacial cone beam computed tomography // Seminars in Orthodontics. - 2009. - Vol. 15, N 1. - P. 2-13. - DOI: 10.1053/j.sodo.2008.09.001. 